\title{
LEITURA EM DOM CASMURRO: O NARRADOR, O EDITOR E O LEITOR
}

\section{READING IN DOM CASMURRO: THE NARRATOR, THE EDITOR AND THE READER}

\author{
Sandra Regina Tornquist* \\ Flávia Brocchetto Ramos*
}

RESUMO: Este artigo tem por objetivo analisar a leitura em Dom Casmurro, a partir de três focos: as leituras realizadas pelo narrador e citadas no texto, o modo como o narrador trata o leitor e as tentativas de diálogo que estabelece e, por último, os procedimentos empregados pelo editor, visando à comunicação com um público iniciante. O estudo segue princípios da História da Leitura apontados, principalmente, por CHARTIER (2002), DARNTON (1990) e ZILBERMAN (2001). Destaca-se que, mesmo com as tentativas de diálogo que o narrador propõe ao leitor, o texto é denso e, desse modo, o editor procura interferir para reduzir a distância estética entre o horizonte do texto e o do leitor jovem contemporâneo.

PALAVRAS-CHAVE: Dom Casmurro, mediação, leitura.

ABSTRACT: The objective of this article is to analyze the reading in Dom Casmurro, through three focuses: the readings that the narrator made and mentions in the text, the way the narrator treats the reader and the dialog attempts that he establishes and, finally, the procedures used by the editor, aiming the communication with a beginning public. The study follows principles of the History of the Reading, pointed, mainly, by CHARTIER (2002), DARNTON (1990) and ZILBERMAN (2001). Have to be considered that, in spite of the attempts of dialog the narrator proposes to the reader, the text is dense and, so, the editor tries to interfere to reduce the esthetic distance from the horizon of the text to the horizon of the young contemporary reader.

KEY WORDS: Dom Casmurro, mediation, reading.

\footnotetext{
* Aluna do Mestrado em Letras - Leitura e Cognição - da Universidade de Santa Cruz do Sul - UNISC. Santa Cruz do Sul - RS. Email: sareto@ universiabrasil.net.

** Professora do PPGL Leitura e Cognição/UNISC e Departamento de Letras/UCS. Email: ramos.fb@gmail.com.
} 



\section{LEITURA EM DOM CASMURRO: O NARRADOR, O EDITOR E O LEITOR'}

\section{Introdução}

Reconhecido pela dúvida que instaura e pelo modo como é escrito, o romance Dom Casmurro, de Machado de Assis, publicado em 1899, é um dos textos mais bem construídos da literatura brasileira, revelando a genialidade de um escritor que conquistou grande reconhecimento tanto nacional, quanto internacionalmente. Machado dá seguimento a uma tendência realista instaurada com o romance Memórias póstumas de Brás Cubas, em 1881.

O narrador observador, distanciado dos fatos, não aparece nessa obra. Pelo contrário, a narração da história é feita pelo protagonista Bento Santiago, transformado, pela idade e pelos acontecimentos, em Dom Casmurro. $\mathrm{O}$ discurso do narrador, que vive a dúvida quanto à fidelidade ou não de sua esposa, abre espaço para uma variedade de leituras possíveis, provocando discussões entre os receptores quanto à existência ou não da traição por parte de Capitu.

A incerteza quanto ao sentido construído pela leitura é um aspecto inerente ao texto literário, uma vez que a polissemia é uma marca da arte. Conforme afirma Regina Zilberman, "a flexibilidade de cada texto decorre

\footnotetext{
${ }^{1}$ Estudo desenvolvido durante a disciplina História da Leitura.
} 
da habilidade em responder de modo distinto a cada leitor ou aos segmentos variados de público; decorre igualmente da propriedade de o destinatário intervir na obra."' . Assim, cada leitor encontra, nas obras que lê, suas próprias dúvidas e respostas, já que, "despertado o imaginário por força da leitura, nada mais pode contê-lo ou domá-lo."3.

E essa característica da pluralidade de leituras tem, em Dom Casmurro, um reforço especial, devido ao recorrente apelo do narrador à sua experiência de leitor. Constata-se que Bento era um grande conhecedor da literatura universal, afeito a obras da tradição e isso, sem dúvidas, reflete na forma como é contada a história. Por outro lado, ele revela sua preocupação com a compreensão da história que escreve e trava conversas com o leitor, tratando-o como um conhecido íntimo.

Além desse narrador/leitor, também o editor desempenha papel importante na constituição da obra. Para este estudo, tomamos como objeto um exemplar publicado pela Editora Ática, Série Bom Livro, destinado, possivelmente, a escolares.

Visando estudar o leitor e suas representações na obra citada, este artigo está organizado em três etapas: num primeiro momento, será apresentado o narrador da história, o leitor Bento Santiago, buscando-se demonstrar as influências de suas leituras na obra que produz; em seguida, este mesmo narrador é analisado quanto à sua relação com o possível leitor da história. $\mathrm{Na}$ terceira etapa, parte-se para a análise da intervenção do editor, a fim de adaptar a obra ao público previsto. Após estes três momentos, apresentamse algumas considerações, que apontam para a importância da leitura em cada etapa de constituição de uma obra, desde sua criação, sua formatação até a recepção.

\section{O narrador enquanto leitor}

Bentinho é um narrador culto que evidencia marcas de sua condição social. Nasceu em uma família de nível social confortável, tendo em casa bons exemplos em termos de instrução e de leitura: tio Cosme era advogado; José Dias, um agregado da família: "Era lido, posto que de atropelo, o bastante para divertir ao serão e à sobremesa, ou explicar algum fenômeno,

\footnotetext{
${ }^{2}$ ZILBERMAN, Regina. Fim do livro, fim dos leitores? São Paulo: SENAC, 2001. p. 91.

${ }^{3}$ Ibidem, p. 27.
} 
falar dos efeitos do calor e do frio, dos pólos e de Robespierre." 4 . O próprio pai, que falecera jovem, fora deputado, cargo que também remete à idéia de que possuía boa instrução. Além dessas figuras masculinas, vale destacar o papel da mãe, D. Glória, e da prima desta, D. Justina, que cuidavam da formação religiosa - Bentinho estudou num seminário. Os efeitos dessa formação podem ser percebidos através das repetidas citações de passagens bíblicas no romance. O narrador também recebeu, desde cedo, uma boa formação, tendo aprendido ainda em casa "as primeiras letras, latim e doutrina." 5 .

Talvez o ambiente favorável à leitura tenha desencadeado a formação literária do narrador e, ainda, a condição de autor de sua história, pois Bentinho assume o discurso. Mesmo no período em que está escrevendo Dom Casmurro, conserva o hábito da leitura: "Em verdade, pouco apareço e menos falo. Distrações raras. O mais do tempo é gasto em hortar, jardinar e ler; como bem e não durmo mal."'. Note-se que a leitura não é referida somente como distração, mas está entre as funções diárias. $\mathrm{E}$ a recorrência ao uso da palavra "ler" no romance é significativa da presença dessa ação constante na vida do narrador.

Desde o início do livro, são freqüentes as citações a obras clássicas da literatura universal e a personalidades históricas, bem como à Bíblia, revelando, por um lado, a formação cultural de um indivíduo instruído e de condição social favorável, e, por outro, o legado que traz por ser membro de uma família religiosa e por ter sido seminarista.

No capítulo II, quando Bento Santiago está descrevendo os motivos que o levaram a escrever o livro, cita Fausto, importante obra de Goethe: "Talvez a narração me desse a ilusão, e as sombras viessem perpassar ligeiras, como ao poeta, não o do trem, mas o do Fausto: Aí vindes outra vez, inquietas sombras...?"' É por olhar/ler o entorno e pelo diálogo entre esse entorno e as memórias de leituras do narrador que se delineia o motivo de escrever sobre sua vida. O narrador confessa:

Fiquei tão alegre com a idéia que ainda agora me treme a pena na mão. Sim, Nero, Augusto, Massinissa, e tu, grande César, que me incitas a fazer os meus

\footnotetext{
${ }^{4}$ ASSIS, Machado de. Dom Casmurro. 30a. ed. São Paulo: Ática, 1996. p. 19.

${ }^{5}$ Ibidem, p. 26.

${ }^{6}$ Ibidem, p. 15.

${ }^{7}$ Ibidem, p. 15.
} 
comentários, agradeço-vos o conselho, e vou deitar ao papel as reminiscências que me vierem vindo. Deste modo, viverei o que vivi, e assentarei a mão para alguma obra de maior tomo. ${ }^{8}$

No trecho citado, nota-se a referência a personagens históricos, os quais eram conhecidos do narrador desde a infância, já que no centro do teto da casa em que residira havia a pintura dos referidos personagens, o que demonstra que o próprio ambiente em que vivia o jovem Bentinho era propício para que alcançasse um alto nível de instrução e conhecimento cultural.

O ato de escrever a sua vida é, para o narrador, mais do que uma forma de registrá-la, avança no sentido de que, ao escrevê-la, as ações podem ser vividas de novo, os fatos vão ser recordados e atualizados pela memória do narrador. À medida que os fatos são apontados, são associados a obras literárias e o sentido do que é narrado é iluminado pela vivência que o narrador tem da leitura literária, a qual o acompanha desde a juventude, conforme é possível perceber, por exemplo, no capítulo LV, em que ele, enquanto ainda estava no seminário, tentara produzir um soneto e, para buscar inspiração, evocara "alguns dos sonetos célebres e [notara] que os mais deles eram facílimos." .

Possuidor de vasto conhecimento literário, Bento Santiago o transfere para sua obra. Assim, no capítulo VII, faz uma referência à "boceta de Pandora”, da mitologia grega, quando está descrevendo o retrato dos pais que tem na parede de sua casa e compara a felicidade conjugal deles com a de ter a sorte grande, defendendo, por conseqüência, as loterias: "Concluo que não se devem abolir as loterias. Nenhum premiado as acusou ainda de imorais, como ninguém tachou de má a boceta de Pandora, por lhe ter ficado a esperança no fundo; em alguma parte há de ela ficar." ${ }^{10}$. No capítulo LXI, intitulado "A vaca de Homero", Bentinho, ao receber uma visita do agregado José Dias, o qual encabeça o plano de tirar o jovem do seminário, associa o episódio a um fato registrado na Ilíada: o guerreiro Menelau rodeia Pátroclo (companheiro ferido) decidido a matar quem se aproximasse do amigo, assim como faria uma vaca inexperiente ao ver alguém se aproximando

\footnotetext{
${ }^{8}$ Ibidem, p. 15

${ }^{9}$ Ibidem, p. 85.

${ }^{10}$ Ibidem, p. 21-22.
} 
de sua cria. Tais passagens demonstram que o narrador conhece obras do mundo grego.

No capítulo IX, o narrador apresenta um tenor italiano, amigo já falecido, segundo o qual "a vida é uma ópera”. Ao apresentar essa definição, o tenor cita uma passagem bíblica e uma obra de Shakespeare, revelando seu alto grau de instrução, que se reflete também em Bentinho. O narrador nutre-se de literatura, não apenas pelo contato com os livros, mas através de conversas com amigos cultos.

Merece ser referido, também, um drama que revela ter forte influência sobre o narrador, trata-se de Otelo, de Shakespeare, cuja trama tem as mesmas motivações da história de Bentinho, o ciúme e a suspeita de traição. O narrador chega a consagrar três capítulos a essa obra, um com o título "Uma ponta de Iago"11, em que compara José Dias com o personagem de Otelo que desperta no protagonista o ciúme e a dúvida quanto à fidelidade de sua amada. Um segundo, intitulado "Uma reforma dramática" ${ }^{12}$, em que Santiago propõe que as peças de teatro devessem começar pelo fim. "Otelo mataria a si e a Desdêmona no primeiro ato, os três seguintes seriam dados à ação lenta e decrescente do ciúme, e o último ficaria só com as cenas iniciais da ameaça dos turcos, as explicações de Otelo e Desdêmona, e o bom conselho do fino Iago: 'Mete dinheiro na bolsa."' ${ }^{3}$. Com tal atitude, o narrador tinha por objetivo possibilitar que, ao final, o expectador levasse uma boa impressão do que assistira e não o impacto da violência.

O terceiro capítulo sobre Otelo recebe o próprio título do drama shakespeariano; nele Santiago narra sua ida ao teatro para assistir a essa peça e como se sentiu convencido do que devia fazer: "O último ato mostrou-me que não eu, mas Capitu devia morrer." ${ }^{14}$. O narrador mostra a influência da ficção no modo como entende sua vida, ou melhor, como revisita fatos vividos. A significação da peça é mesclada pelas inquietações do expectador, que depois são traduzidas pela escrita do narrador.

As numerosas obras citadas por Santiago contribuem para revelar a influência que a leitura tem em sua vida, mostrando que o leitor se modifica pelo que lê, as obras ampliam as percepções, os horizontes do leitor, apontam respostas e caminhos. A última citação de Santiago reforça essa idéia:

\footnotetext{
${ }^{11}$ Ibidem, p. 93.

${ }^{12}$ Ibidem, p. 106.

${ }^{13}$ Ibidem, p. 106.

${ }^{14}$ Ibidem, p. 171.
} 
"Jesus, filho de Sirach, se soubesse dos meus primeiros ciúmes, dir-me-ia, como em seu cap. IX, vers. 1: 'Não tenhas ciúme de tua mulher para que ela não se meta a enganar-te com a malícia que aprender de ti."' ${ }^{15}$. Com essa referência, o narrador revela que se tivesse se deixado conduzir pela leitura bíblica, talvez pudesse ter salvo sua relação com Capitu. Assim, as escolhas feitas na leitura são também, de certa forma, escolhas de vida.

Sintetizando, pode-se afirmar que Dom Casmurro é uma obra marcada por recorrentes pontos de intertextualidade, devido, de certa forma, ao nível de instrução de seu narrador. Ao trazer para sua história fragmentos de obras a que teve acesso ao longo da vida, o narrador enriquece seu texto e demonstra que a leitura o constitui como sujeito, ela é parte de sua experiência. A atitude de dialogar com a voz de outros é própria da escrita, pois, como destaca Julia Kristeva, "todo texto é absorção e transformação de um outro texto."16. O escritor não cria sua obra a partir do nada, ela sempre é sustentada por toda a experiência de leitura e de vida de seu autor. Dessa forma, a qualidade de Dom Casmuro é fruto não apenas da genialidade inata de seu criador, mas também de toda a bagagem de leituras que ele trazia e que, voluntária ou involuntariamente, transparecem em sua produção escrita.

\section{O tratamento dispensado pelo narrador ao leitor}

Dom Casmurro é escrito porque seu narrador está cansado da monotonia e pensa encontrar na escrita uma forma de "atar as duas pontas da vida, e restaurar na velhice a adolescência." ${ }^{17}$. Essa mesma proposta aparece mais tarde em outra obra da literatura brasileira: São Bernardo, de Graciliano Ramos. O desejo de reviver ou de visitar a adolescência já fez com que Bentinho reproduzisse, na casa em que vivia no momento da escritura, aquela de sua infância. A construção, porém, não dava conta de reconstruir sua história, e por isso "os bustos pintados nas paredes entraram a falar-me e a dizer-me que, uma vez que eles não alcançavam reconstituir-me os tempos idos, pegasse da pena e contasse alguns." ${ }^{18}$. Era necessário achar outra forma de encontrar-se com a juventude e o ato de escrever sua vida foi a forma escolhida por este narrador.

\footnotetext{
${ }^{15}$ Ibidem, p. 184.

${ }^{16}$ KRISTEVA, Julia. Introdução à semanálise. Tradução Lúcia Helena França Ferraz. São Paulo: Perspectiva, 1974. p. 64.

${ }^{17}$ ASSIS, Machado de. Dom Casmurro. 30a . ed. São Paulo: Ática, 1996. p. 14.

${ }^{18}$ Ibidem, p. 15.
} 
Consciente do tipo de público que irá encontrar em sua época e buscando estabelecer com ele uma relação de cumplicidade, Santiago dedica ao leitor uma atenção diferenciada, revelada nas explicações que dá e nas formas de tratamento. Trata-se de uma relação de cumplicidade, em que, conforme Zilberman e Lajolo, "narrador e ouvinte dividem um espaço íntimo." 19 .

Um exemplo bem característico da solidariedade dispensada ao leitor aparece já no primeiro capítulo, quando o narrador explica o título da obra e dispensa o leitor de consultar a palavra "casmurro" no dicionário: "Não consultes dicionários. Casmurro não está aqui no sentido que eles lhe dão, mas no que lhe pôs o vulgo de homem calado e metido consigo. Dom veio por ironia, para atribuir-me fumos de fidalgo." ${ }^{20}$. Através dessas atitudes, o narrador orienta explicitamente o processo de compreensão do leitor.

Os capítulos seguintes também são reveladores dessa proximidade que o narrador tenta estabelecer, na medida em que passa a apresentar as pessoas que constituem seu círculo familiar e de amizades, a fim de que o leitor possa conhecê-los e compreender-lhes melhor as atitudes e a importância que ocupam na história narrada. Uma passagem bastante esclarecedora, nesse sentido, é a que faz parte do capítulo em que Santiago apresenta sua mãe, Dona Glória: "Tenho ali na parede o retrato dela, ao lado do marido, tais quais na outra casa." ${ }^{21}$. A impressão é que ele fala ao leitor como se este estivesse ao seu lado e pudesse efetivamente ver o retrato.

Também as expressões de tratamento que são usadas por Santiago revelam a tentativa de aproximação. Citem-se como exemplo: "leitor amigo"22, "leitora minha devota" ${ }^{23}$, entre outras. Mas também há momentos em que o narrador afirma que não irá se subjugar à vontade do leitor e apresentará, mesmo que a contragosto deste, os fatos tais como estes transcorreram. Desse modo, assegura o seu compromisso com a verdade, referendando a validade do texto, de modo que o leitor pode confiar tanto nas informações apresentadas na narrativa como nas inquietações confidenciadas. É o que

\footnotetext{
${ }^{19}$ LAJOLO, Marisa; ZILBERMAN, Regina. A formação da leitura no Brasil. São Paulo: Ática, 1996. p. 22.

${ }^{20}$ ASSIS, Machado de. Dom Casmurro. 30a. ed. São Paulo: Ática, 1996. p. 13.

${ }^{21}$ Ibidem, p. 21.

${ }^{22}$ Ibidem, p. 25.

${ }^{23}$ Ibidem, p. 31.
} 
se passa, por exemplo, em: "não hei de trocar as datas à minha vida só para agradar às pessoas que não amam histórias velhas." ${ }^{24}$.

A ânsia por mostrar a verdade está presente no discurso do narrador, pois pretende convencer o leitor de que aquilo que ele, enquanto protagonista da história, afirma é verdadeiro e deve ser aceito como tal. É o que aparece em: "Capitu era Capitu, isto é, uma criatura mui particular, mais mulher do que eu era homem. Se ainda não o disse, aí fica. Se disse, fica também. Há conceitos que se devem incutir na alma do leitor, à força de repetição." ${ }^{25}$.

É dessa forma que Santiago vai conquistando o leitor, envolvendo-o na sua história de vida, delegando-lhe a tarefa de preencher as lacunas que vai deixando no texto, chegando, por fim, ao ponto de pedir-lhe concordância sobre a mudança que se deu em Capitu: "tu concordarás comigo; se te lembras bem da Capitu menina, hás de reconhecer que uma estava dentro da outra, como a fruta dentro da casca." ${ }^{26}$. Não que o narrador necessite dessa concordância do leitor, mas é uma forma de elevar a importância deste, ao nível de alguém que se procura para fazer uma confidência, esperando compreensão e justificação.

Percebe-se, assim, que o narrador alterna sua atitude frente ao leitor, dependendo do efeito que pretende gerar. Em boa parte da obra, ele tutora, orienta, por exemplo, no final do capítulo XVIII, declara: "Conto estas minúcias para que melhor se entenda aquela manhã da minha amiga; logo virá a tarde, e da manhã e da tarde se fará o primeiro dia, como no Gênesis, onde se fizeram sucessivamente sete." ${ }^{27}$. Esses esclarecimentos revelam que a história narrada está apenas começando e que muito ainda haverá para ser contado. Já no capítulo LVII, percebe-se a preocupação do narrador de não ofender ou escandalizar o seu leitor, ou mais especificamente sua leitora, com o que escreve. Assim, antes de contar um incidente da época do seminário, ele cria este capítulo "De preparação", alegando que, por mais composto que lhe saia o próximo, "há sempre no assunto alguma coisa menos austera, que pede umas linhas de repouso e preparação. Sirva este de preparação." ${ }^{28}$. Bentinho não apenas conta uma história, mas também busca estratégias de mobilização para enredar o leitor.

\footnotetext{
${ }^{24}$ Ibidem, p. 16.

${ }^{25}$ Ibidem, p. 52.

${ }^{26}$ Ibidem, p. 184.

${ }^{27}$ Ibidem, p. 39.

${ }^{28}$ Ibidem, p. 87-88.
} 
Mas o narrador também desafia o seu leitor e chega a sugerir-lhe que abandone a leitura, se não estiver sendo capaz de perceber o que está deixando nas entrelinhas. Desse modo, acaba alertando que o interlocutor tem um papel na construção do texto, pois deve adentrar na narrativa e descobrir o que não está dito. É o que ocorre no capítulo em que narra uma visita que José Dias lhe faz no seminário e levanta a idéia de Capitu casar-se com um "peralta" de sua rua, o que deixa Bentinho enciumado, imaginando que "trocariam flores e..." ${ }^{29}$. Essas reticências devem ser completadas pelo leitor, conforme o narrador declara no parágrafo seguinte: "E... quê? Sabes o que é que trocariam mais; se o não o achas por ti mesmo, escusado é ler o resto do capítulo e do livro, não acharás mais nada, ainda que eu o diga com todas as letras da etimologia." ${ }^{30}$. Note-se que, mesmo nessa atitude desafiadora, há uma certa orientação, uma forma de guiar o pensamento do leitor.

Também a atitude de discordância em relação ao que é narrado é motivada por ele mesmo, como no capítulo XLV, intitulado de forma sugestiva de "Abane a cabeça, leitor" ${ }^{31}$. Essa frase, que também inicia o capítulo, é inserida após uma discussão entre Bentinho e Capitu, em que esta prometera que ele seria o padre que batizaria o primeiro filho dela.

Após a frase que dá título ao capítulo, o narrador acrescenta:

faça todos os gestos de incredulidade. Chegue a deitar fora este livro, se o tédio já o não obrigou a isso antes; tudo é possível. Mas, se o não fez antes e só agora, fio que torne a pegar do livro e que o abra na mesma página, sem crer por isso na veracidade do autor. Todavia, não há nada mais exato. ${ }^{32}$

Note-se que mesmo quando pressupõe a discordância ou o descontentamento do leitor, o narrador é capaz prever-lhe as atitudes, tão bem conhece (ou finge conhecer) o público que lerá sua obra. Quanto a este público previsto, também é interessante notar que Santiago o considera um público bastante religioso, o que é perceptível por diversas referências, como o já citado exemplo "leitora minha devota" 33 , e ainda "padre que me lês" "leitora

\footnotetext{
${ }^{29}$ Ibidem, p. 94.

${ }^{30}$ Ibidem, p. 94.

${ }^{31}$ Ibidem, p. 74.

${ }^{32}$ Ibidem, p. 74.

${ }^{33}$ Ibidem, p. 31.

${ }^{34}$ Ibidem, p. 101
} 
castíssima" ${ }^{35}$, além dos pedidos de desculpas por atitudes pouco cristãs e a busca de concordância em atos relacionados à religiosidade: "se és religioso, haverás buscado alguma vez conciliar o céu e a terra." ${ }^{36}$.

Por fim, vale também destacar que o narrador dá ao leitor, explicitamente, certa liberdade para preencher as lacunas que ele tenha deixado em sua história, conforme expresso em: "É que tudo se acha fora de um livro falho, leitor amigo. Assim preencho lacunas alheias; assim podes também preencher as minhas." ${ }^{37}$. Ao dar ao leitor essa liberdade, deixa-o livre para decidir sobre a fidelidade ou infidelidade de Capitu, que é uma das incertezas sugeridas pela obra.

O leitor previsto pelo narrador tem autonomia, ele pode interferir no esquema proposto pela obra. O narrador, ao apresentar a história, vai orientando, desafiando e, de certa forma, moldando seu público. Tais procedimentos auxiliam o leitor a entender o texto.

\section{Interferências do editor}

Entre autor e leitor há um, às vezes, longo, caminho a ser percorrido por uma obra, e os editores muitas vezes desempenham papel essencial nesse "circuito das comunicações" ${ }^{38}$, selecionando as obras a serem publicadas e adaptando-as conforme o público que lhe é previsto.

Tomando o caso da obra analisada neste artigo, na sua edição publicada pela Série Bom Livro, da Editora Ática, pode-se perceber uma significativa preocupação do editor em tornar os termos e as expressões próprios do período em que a obra foi escrita acessíveis aos leitores/estudantes da atualidade, já que este é o grande público previsto.

Nota-se a preocupação da editora em deixar claro, já na página inicial do exemplar, alguns aspectos. Neste sentido, apresenta, logo abaixo do título da obra, a expressão: "TEXTO INTEGRAL", seguido de: "Cotejado com a edição crítica do Instituto Nacional do Livro." ${ }^{39}$. Tais dados parecem ter a finalidade de esclarecer ao professor sobre a procedência da obra, caracterizando a seriedade que envolve a publicação. Também a ortografia do texto

\footnotetext{
${ }^{35}$ Ibidem, p. 87.

${ }^{36}$ Ibidem, p. 114.

${ }^{37}$ bidem, p. 90 .

${ }^{38}$ Termo empregado por Robert Darnton no capítulo “O que é a história dos livros?”, parte integrante da obra O beijo de Lamourette. São Paulo: Companhia das Letras, 1990.

${ }^{39}$ SSIS, Machado de. Dom Casmurro. 30a. ed. São Paulo: Ática, 1996. p. 1.
} 
foi atualizada, obedecendo ao sistema ortográfico vigente, o que novamente reflete a preocupação com a compreensão do leitor. Ao final do romance, constam 30 páginas sobre a vida e a obra de Machado de Assis, escritas por Carlos Faraco, revelando o enfoque didático da edição, uma vez que as escolas, em geral, valorizam esse conhecimento.

No interior da obra são incluídas 83 notas de rodapé, que visam a informar sobre diversos termos empregados pelo narrador, que podem ser desconhecidos do leitor. Nesse sentido, incluem-se diferentes categorias de notas, relacionadas aos diversos elementos que possam ser desconhecidos do público previsto.

Assim, uma das categorias de notas presentes na obra é a que traz explicações sobre o modo de viver da época, móveis, vestuário, como aparece na nota 5:

Presilhas, rodaque e gravata de mola: presilhas são cordões próprios para prender, apertar e esticar (no caso, as calças); rodaque, uma espécie de colete, gravata de mola, a que tem por dentro, como diz o texto, "um aro de aço". O "agregado" José Dias representa bem um tipo da sociedade brasileira escravocrata do século XIX: o "homem livre", sem posses, que vive à sombra da camada proprietária, através de relações de favor. ${ }^{40}$

O editor contextualiza o uso dos acessórios mencionados, relacionando-os ao personagem que os utiliza e ao contexto histórico, num esforço para auxiliar o leitor a visualizar mentalmente o espaço e o tempo em que se passa o romance, uma vez que os elementos citados não estão presentes na contemporaneidade e a própria estrutura da sociedade é diferenciada. Nessa atitude de buscar a contextualização, o editor inclui sua leitura da obra, ou seja, a forma como percebe o ambiente, os personagens e os demais elementos do romance.

Uma segunda categoria de notas é a que faz referência a pessoas célebres, como ocorre com Junqueira Freire, mencionado em comparação com um colega de seminário de Bentinho que também escrevia poemas. A apresentação é feita da seguinte maneira: "poeta baiano, Junqueira Freire tornou-se frade sem ter vocação. Sua poesia expressa o dilaceramento entre o temor religioso e um erotismo fremente e delirante. O livro a que o texto

\footnotetext{
${ }^{40}$ Ibidem, p. 17.
} 
se refere é Inspirações do claustro, publicado em 1855, livro que esteve na moda nessa época." ${ }^{41}$.

Nesse grupo também se incluem as personalidades políticas, como é o caso de Franklin, assim apresentado:

Benjamin Franklin (1706-1790), estadista, físico e publicista americano, foi um dos mentores da Independência dos Estados Unidos, negociou a aliança de seu País com Luís XVI, na França, inventou o pára-raios e, ainda, proferiu aforismos ou ditos sentenciosos como o citado na passagem. ${ }^{42}$

Igualmente, eventos históricos de repercussão são explicados em notas de rodapé, criando mais uma categoria. Um exemplo desse tipo de nota é a de número 59, que se refere à Guerra da Criméia, que servira de motivo para uma acirrada argumentação entre o narrador, ainda em sua juventude, e Manduca, um menino da vizinhança que tinha lepra.

Como o narrador havia sido seminarista, aprendera latim e vivia num ambiente bastante culto, há, na obra, várias palavras e frases em línguas estrangeiras, especialmente em latim, que também foram traduzidas pelo editor nas notas de rodapé, muitas vezes acompanhadas de uma explicação, quando se tratavam de frases célebres, como é o caso de In hoc signo vinces:

Latim, "por este signo vencerás". Esta frase aparece junto de uma cruz no estandarte de Constantino, imperador romano que fixou o cristianismo como religião no império, na altura do ano $313 \mathrm{~d}$. C. É, pois, um símbolo religioso invertido ironicamente nesta passagem de Dom Casmurro, tomando o sentido de "por este signo (o do comércio) vencerás (na vida)". ${ }^{43}$

Note-se que, além da explicação sobre o significado da frase e sua origem, o editor inclui também uma orientação ao leitor sobre a intenção com que a mesma foi utilizada na obra. Ao incluir essa observação, o editor demonstra a preocupação em tutorar a leitura de seu público, julgando-o despreparado para produzir sentido de forma autônoma.

\footnotetext{
${ }^{41}$ Ibidem, p. 83.

${ }^{42}$ Ibidem, p. 113.

${ }^{43}$ Ibidem, p. 132.
} 
Outra categoria que vem juntar-se às anteriores para compor as notas do editor, é a que se refere a termos e expressões pouco conhecidos ou em desuso, como é o caso de jarretear, verbo que significa, de acordo com a nota do editor, "amputar, tirar um pedaço." ${ }^{4}$. É interessante notar, porém, que são incluídas nesta lista algumas palavras relativamente populares, como é o caso de pirâmides. Mesmo que o público estudantil seja o leitor previsto, é provável que tenha ao menos alguma noção do que sejam pirâmides. Dessa forma, pela inclusão de notas como esta, parece que o editor subestima a capacidade de seu público.

A última categoria a ser citada é justamente a mais freqüente e referese às muitas obras, personagens e autores famosos citados pelo narrador que são apresentados ao leitor, por serem supostamente desconhecidos deste.

Observe-se a apresentação de Aquiles: "personagem histórica d'A Ilíada de Homero - poema épico da Antiga Grécia onde se narra a guerra de Tróia." ${ }^{45}$. Por tratar-se de personagem da uma literatura menos acessível ao estudante, essa apresentação é útil e se justifica.

No entanto, nas notas do editor incluem-se também obras e autores nacionais, como no exemplo já citado de Junqueira Freire, que deve ser estudado nas aulas de literatura brasileira, o que reforça, de certo modo, a idéia já apresentada de que o editor subestima seu público-alvo.

Essa suposição torna-se mais evidente se observadas as numerosas notas referentes à Bíblia, livro que se supõe minimamente conhecido, num país católico, como o Brasil. Assim, a descrição do Gênesis, como "primeiro livro da Bíblia, em que se descreve a criação do mundo e da humanidade" ${ }^{46}$, pode parecer, para muitos estudantes, desnecessária.

Dessa forma, na intenção de tornar o texto o mais acessível ao jovem leitor, o editor, por vezes, acaba criando notas que não acrescentam dados novos e podem acabar atrapalhando a fruição do texto, como já ocorreu no passado, com os "livros azuis", em que as dificuldades de compreensão eram, por vezes, "introduzidas nos textos exatamente pelas operações que desejam tornar sua leitura mais fácil." ${ }^{47}$.

\footnotetext{
${ }^{44}$ Ibidem, p. 90.

${ }^{45}$ Ibidem, p. 35.

${ }^{46}$ Ibidem, p. 39.

${ }^{47}$ CHARTIER, Roger. Os desafios da escrita. Tradução Fulvia M. L. Moretto. São Paulo: UNESP, 2002. p. 70.
} 
Por fim, vale também fazer uma referência à capa da trigésima edição de Dom Casmurro, da Série Bom Livro, em que se destaca a imagem de três pessoas que, a partir da leitura do romance, se deduz que sejam Bento Santiago, Capitu e o filho Ezequiel. Eles estão juntos, Capitu abraçada ao filho e Santiago atrás dos dois, mas olhando discretamente para o lado, onde se encontra um quadro de Escobar. Para o leitor da obra, torna-se fácil identificar esses personagens e deduzir o que Santiago busca ao olhar para o quadro, ou seja, a semelhança entre Escobar e Ezequiel, que, pela imagem, é explícita. Assim, percebe-se também um direcionamento da leitura já na capa da obra, que leva a aceitar a traição de Capitu como fato, embora o romance de Machado de Assis não o afirme. O editor, dessa forma, interfere no texto original e restringe a liberdade de interpretação que o romance oferece.

\section{Considerações Finais}

Os três aspectos estudados na obra Dom Casmurro são reveladores do fato de que uma obra não se restringe à história que está registrada no papel, ela vem sempre carregada de significações que não estão necessariamente explícitas, as quais o leitor constrói, através da leitura atenta.

O leitor tem um repertório e, ao interagir com o texto, traz sempre uma bagagem de experiências anteriores de leitura, além de sua formação intelectual e vivência sociocultural. Santiago coloca no seu texto a sua bagagem pessoal e estende-a perante o leitor, um leitor projetado como um amigo, um confidente, mas que tem, muito provavelmente, outro nível de instrução e de experiências de leitura, o que é demonstrado pelo tutoramento assumido, pelo narrador, no decorrer da narrativa.

Preocupado com essa distância entre o conhecimento do narrador e o mundo do leitor, o editor da Série Bom Livro, partindo da projeção que faz de seu público-alvo, interfere na obra, acrescentando-lhe dados para preencher lacunas que acredita que não seriam compreendidas por um leitor iniciante.

Ao chegar ao púbico final, ao leitor de carne e osso, a obra é novamente transformada, pois este faz do lido uma produção própria, reinventando o conteúdo dos textos à sua maneira, associando-o às suas vivências individuais e à sua formação sócio-cultural, gerando, assim, uma concretização peculiar do texto, o que tem permitido, ao longo dos tempos, visões tão diferenciadas de Dom Casmurro. A história contada deixa de ser a de Bentinho, assume outras dimensões: pode ser a história da sociedade brasileira do final do século XIX, pode ser a história de dúvida do homem contemporâ- 
neo, pois enquanto o texto continuar dialogando com o público, continua respondendo às perguntas que o homem faz.

Enfim, constata-se neste estudo a preocupação de mediar a literatura. O narrador descortina ao leitor uma série de obras que conhece, cita autores e personagens, a partir da sua vida. Mostra, portanto, a leitura da literatura associada às suas vivências, ou seja, como uma forma de se conhecer. Outro aspecto da mediação da literatura pode estar associado à postura desse narrador, que conversa com o leitor, trata-o amigavelmente e orienta o processo de leitura. Por último, a mediação ocorre por aspectos externos ao enredo, consistindo nas estratégias de divulgação da obra, as quais são desencadeadas por um editor contemporâneo que publica o livro e lhe dá, pois, materialidade. Ao prever o público, seleciona procedimentos que julga tornarem o texto mais acessível ao leitor.

Cada obra tem as suas peculiaridades e, dependendo dos aspectos intrínsecos, como a atuação do narrador e a relação estabelecida com o leitor implícito ou explícito, ou dos extrínsecos, como a interferência do editor num texto, as possibilidades de sentido se alteram. A interação entre leitor e texto é singular, dependendo da natureza do material lido, das indicações

ofertadas pelo texto, que constituem seu horizonte, e das peculiaridades do leitor, ou seja, do seu horizonte. Nesse sentido, cada leitura produz vivências genuínas, partindo do conhecimento que o leitor já detém, num processo em que leitor e leitura transformam-se reciprocamente.

\section{Referências Bibliográficas}

ASSIS, Machado de. Dom Casmurro. 30a . ed. São Paulo: Ática, 1996.

CHARTIER, Roger. Os desafios da escrita. Tradução Fulvia M. L. Moretto. São Paulo: UNESP, 2002.

DARNTON, Robert. O beijo de Lamourette. Mídia, cultura e revolução. São Paulo: Companhia das Letras, 1990.

KRISTEVA, Julia. Introdução à semanálise. Tradução Lúcia Helena França Ferraz. São Paulo: Perspectiva, 1974.

LAJOLO, Marisa; ZILBERMAN, Regina. A formação da leitura no Brasil. São Paulo: Ática, 1996.

ZILBERMAN, Regina. Fim do livro, fim dos leitores? São Paulo: SENAC, 2001. 
